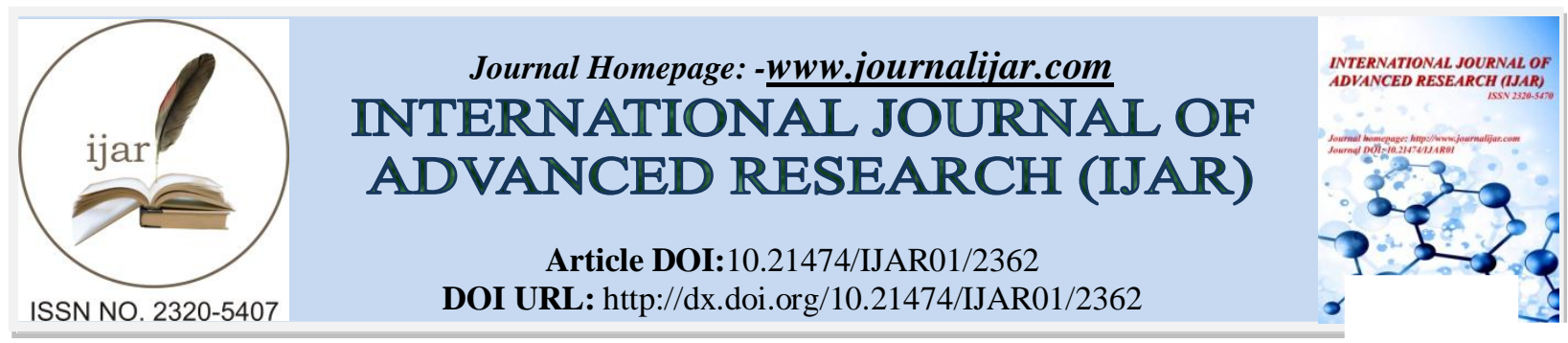

RESEARCH ARTICLE

\title{
SILENT LEARNERS' LANGUAGE COGNITION: A CONTENT ANALYSIS.
}

Ariel E. San Jose, PhD and Mohammed Galal.

Faculty of Foundation Studies Gulf College, Muscat, Oman.

\section{Manuscript Info}

Manuscript History

Received: 18 October 2016

Final Accepted: 20 November 2016

Published: December 2016

Key words:-

cognition, silent learners, content

analysis, gulf college.

\begin{abstract}
The qualitative-content analysis study aimedto determine the cognition, comprehension, and common writing errors committed by the mute and hard-of-hearing learners. Also, it offered suggestions based on the analysis of the results. This study analyzed 10 short-term classroom assessments and learners' $130-150$ word essays. Results of the short-term classroom assessments showed the cognition and noncognition of the different aspects of learning. Positively, mute and hard-of-hearing learners found no or little difficulty in picture name test, yes or no questions, comprehension test with model question, short anecdote reading comprehension, and present and past tenses of (be) verbs. However, they struggled in answering short-responses and were confused with matching type test. It was also observed that they developed techniques like crossing-out, ticking or putting numbers to guide them in choosing their answers. Further, they could draw common words which they knew but they were not conscious of the putting punctuations. In writing, they were comparable with the normal students. They committed misspelled words, omitted letters or words, and added words unnecessary words in a sentence.
\end{abstract}

Copy Right, IJAR, 2016,. All rights reserved.

\section{Introduction:-}

Humans are born with an innate capacity for language (Chomsky, 1957); nonetheless, mute and hard-of-hearing individuals are not exempted in acquiring language for communication (Mathews, 2011) for language acquisition are fundamental to their general cognitive development and their engagement with their surroundings.

It was found that mute and hard-of-hearing individuals lag in language development and subsequent difficulties in school are attributed to their disabilities (Humphries, Kushalnagar, Mathur, Napoli, Padden, Rathmann, and Smith, 2012).This is confirmed by San Jose (2016) who discovered that mute and hard-of-hearing learners have hard time learning a language because they don't have the 'taste of a language'. With this condition (Body language, 2016) mute and hard-of-hearing individualsdevelop creative system of signals from the environment. These signals involve pointing at things, nodding or shaking hands, hand gestures, and performing certain actions that show intentions and meaning. These created systems offer them language-learning opportunities. However, despite this development, these individuals cognition of the text, written and spoken, is yet to be determined.

Goldin-Meadow (2005) mentioned that reading needs familiarity with a language and understanding between that language and the written word. He observed that mute and hard-of-hearing persons are deficient in both but he admitted that reading is possible if hard-of-hearing persons learn American Sign Language (ASL). Once ASL is 
learned, hard-of-hearing learners are able to map between sign language and written text. Previous studies showed (Pardo, 1968) mute students had slow language comprehension, lack abstraction and formation of concepts, and difficulty in adapting new situations; (Kolvin and Fundulis, 1981) found mute persons had speech immaturity; (Fabbretti, Volterra, and Pontecorvo, 1998) discovered language development of deaf children was lower compared to children with normal hearing.

The literatures mentioned above ignited our interest in exploring the cognition and comprehension of the mute and hard-of-hearing learners in our classroom. We understand that there studies conducted in this area; however, no study yet conducted in our school. Thus, this endeavor might be helpful for those teachers who were teaching special needs learners.

\section{Research Questions:-}

This research determined the cognition and comprehension of the mute and hard-of-hearing learners at Gulf College of Oman. Specifically, this research answered the following queries:

1. What is cognition of the mute and hard-or-hearing learners based on short-term classroom assessments?

2. What are the common mistakes committed by the mute and hard-of-hearing in writing?

3. What suggestions may be offer to enhance the cognitive and comprehension skills of the mute and deaf-ofhearing learners?

\section{Theoretical Framework:-}

This research was anchored on the idea of Zone of Proximal Development developed by Vygotsky (1978). Vygotsky defined this theory as "the distance between the actual developmental level as determined by independent problem solving and the level of potential development as determined through problem solving under adult guidance, or in collaboration with more capable peers" (Vygotsky, 1978). In this study, the cognition and understanding of the mute and hard-of-hearing learners were determined so that appropriate assistance may be developed to address the needs of the learners.

Moreover, this study looked into Kimberly Brown's (2014) article "The Limping Chicken", she enumerated some things mute and hard-of-hearing people can do and cannot do. These people can lip-read and understand sign language but need assistance in interpreting some gestures and in reading and writing words. Moreover, it was hard for them to do assumptions and understand too many information.

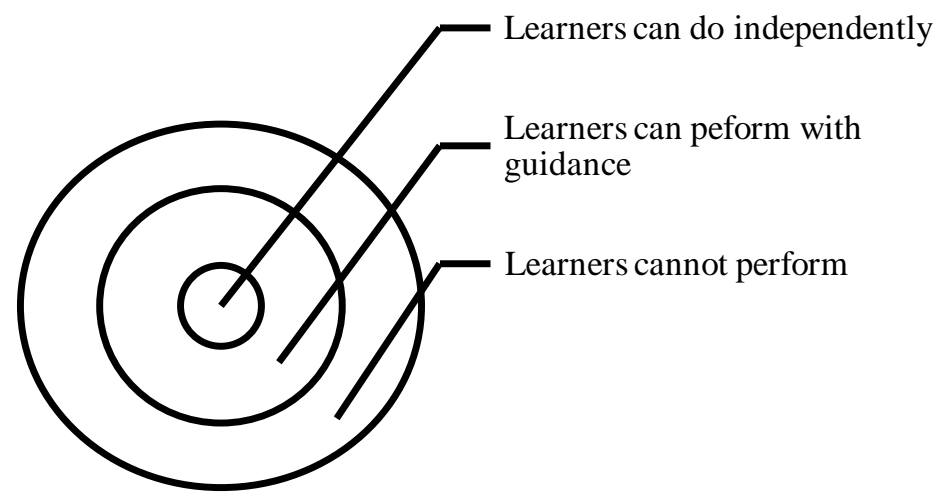

This framework showed the three domains of the students' cognitive development. There were things that learners can do independently, dependently and inability. In this study, the researchers believed that there were tasks the learners could perform freely without the assistance of the teachers; things which they could carry out perfectly with the assistance of someone; and things which they cannot do because those were beyond their proximity.

\section{Method:-}

Presented in this section were the methods used in this research. It specifically included the research design, instrument, and procedures of the study. 


\section{Research Design:-}

This study used descriptive - Content Analysis (CA). Svensson (1984) maintains that descriptive method focuses on the descriptions and emphases on verbal data. Moreover, its intuitive nature is to make interpretation of the data. For Hernani and Ortega (N. D), it involves recording and analysis which focus on current conditionsof individuals. It also involves similarities and differences. Moreover, Adams, Khan and Raeside (2014) points out that descriptive method looks not only facts but also basic assumptions based on the objective thinking. Thus, descriptive method is beyond the gathered data. In this study, the researchers determined and described the cognition and comprehension of the mute and hard-of-hearing students based on their performances in quizzes and writing exercises. Hence, the researchers were not interested on "how" and "why" of the data rather on the "what".

\section{Research Instruments:-}

To gather the pertinent data, the researchers used two materials. First, were the ten activities given to the learners. These activities involved picture identification, reading comprehension with short response, identification with short response, matching type and multiple choices. Second was a constructed six-model essayswith different titles consisted of 130-150 words. Each learner chose one essay to be read and familiarized. After one-week, the learners were asked to write the same essay.

The first materials were used to examine the cognition and understanding of the learners on the topics discussed in class while the second material was used to obtain the memory learners. However, these materials were not used to measure the level of the learners' cognition and comprehension because the number of participants was not statistically viable. Hence, a descriptive presentation of the learners' cognition and comprehension was done.

\section{Participants of the Study:-}

This study did not directly involve the mute and hard-of-hearing learners rather it involved their assessment tasks and writings papers. This study considered only eight secondary materials of the learners for content analysis. The researchers did not consider the entire assessment output of the 17 students because the outputs of the nine learners were incomplete. According to Duncan (1989) samples of content analysis must be 'representative of the sample' from which it was taken while Downe-Wamboldt (1992) suggested that in content analysis detailed procedures need to describe divisive issues under investigation. In this research, the eight samples were seen enough sample for content analysis. Moreover, comprehensive and in depth discussions were provided to explain the topic under investigation.

\section{Results:-}

This section dealt with the results of the evaluation of the materials subjected to content analysis. The information gathered werecategorized according to the research questions of the study.

For the purposes of identification, the researchers assigned code to the evaluated materials. CA referred to Content Analysis; P for the participant; 1 to 8 for the number of the participant; $\mathrm{L}$ for the line; and numeric value for the number of line where the information was obtained.

Moreover, to clearly understand the results of the study, we presented the information using the image projection description method which was previously used by San Jose (2014) to elucidate the findings.

\section{Cognition on Short Term Classroom Assessment}

Deaf and hard-of-hearing learners had no difficulty in identifying the picture-name test.It was also noticed that they developed a technique in identifying the object, just like an ordinary student. They either crossed-out or ticked the name-word of the object if they were done answering an item.

This sample showed the work of CAP4. In this task, all learner-participants papers had perfect scores. It implies that mute and hard-of-hearing participants have higher cognition in naming pictures.

This sample showed the work of CAP4. In this task, all learner-participants papers had perfect scores. It implies that mute and hard-of-hearing participants have higher cognition in naming pictures. 


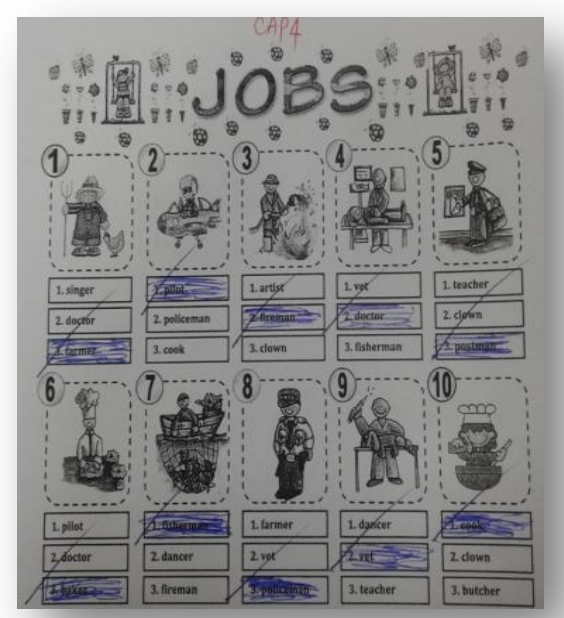

In this sample paper, CAP5 wrote Arabic words in each English word. This technique helped him understand the word. He did this through the aid of a mobile dictionary application.

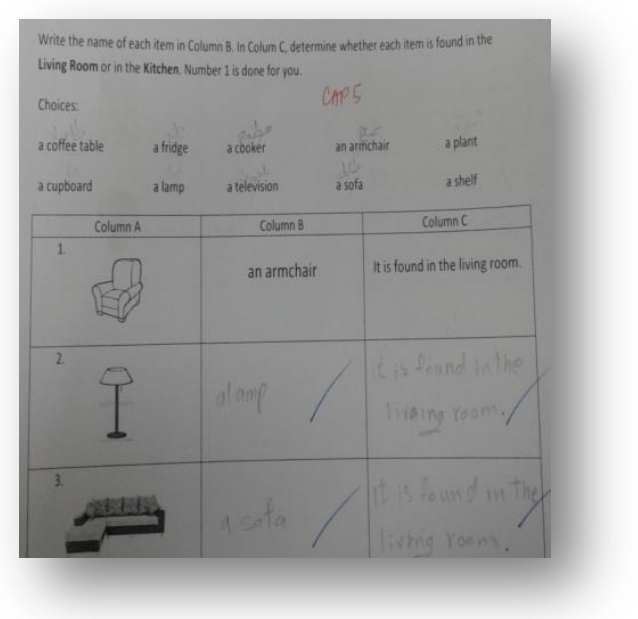

Other students put numbers on each word to indicate the sequence. Students were unable to identify objects which were unfamiliar to them.

In this sample paper, CAP1 marked each English word with a number. This gave him an idea which name-word corresponds to a picture. 


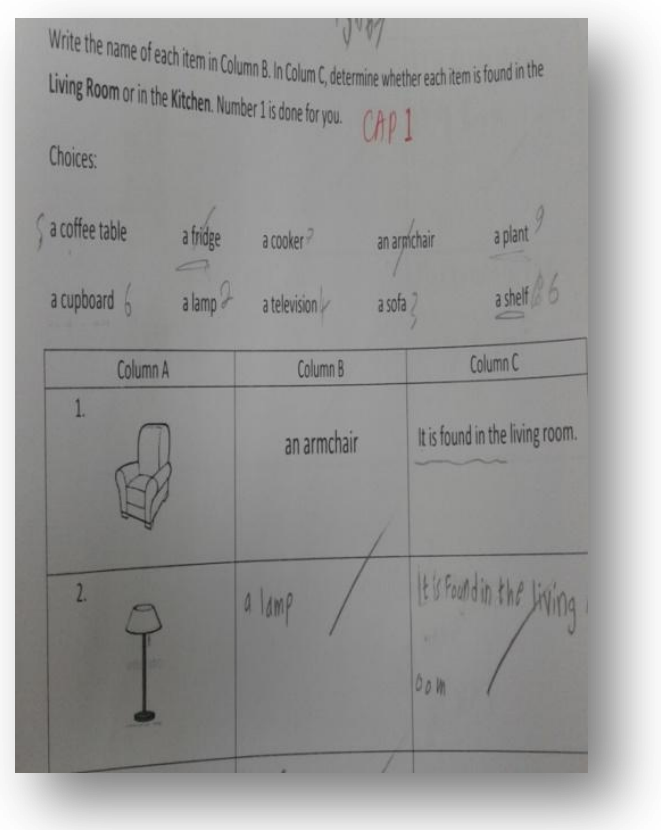

In this sample, CAP8 was able to name some pictures; however, she answered incorrectly other things which are known to her. Unfamiliarity of a learner on a certain object may lead to this situation.

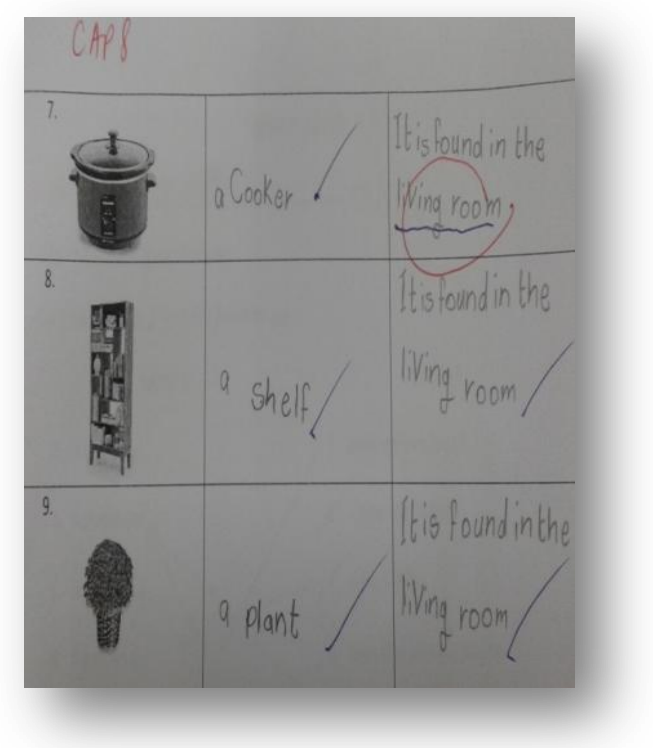

Students struggle in matching the name-word with the description. However, deaf and hard-of-learning learners answer True or False with ease. Also, they struggled in answering questions which require short responses.

In this sample, it showed that CAP 7 was unable to determine where a cupboard can be seen. 


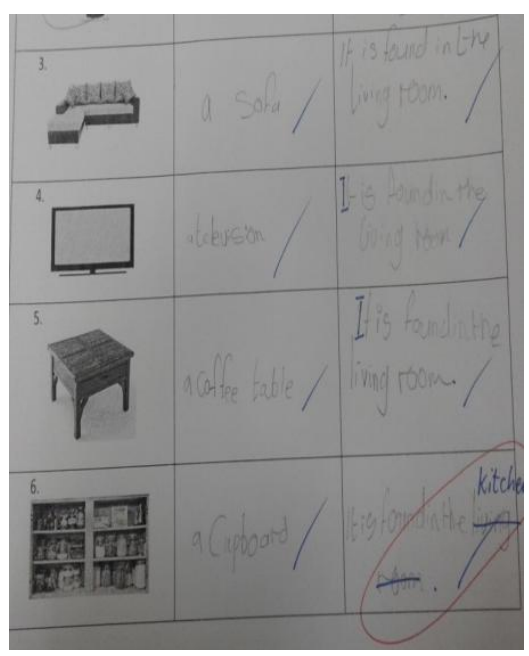

This sample showed that CP5 only responded to the YES or NO questions but failed to indicate her short response.

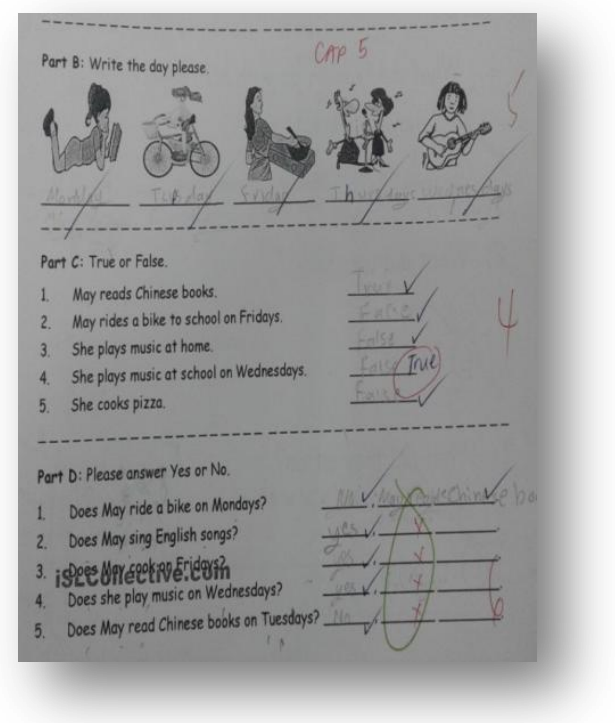

In this sample, CAP 6 was able to complete the short responses; however, two of her answers were not correct, both the Yes or No and short responses. 


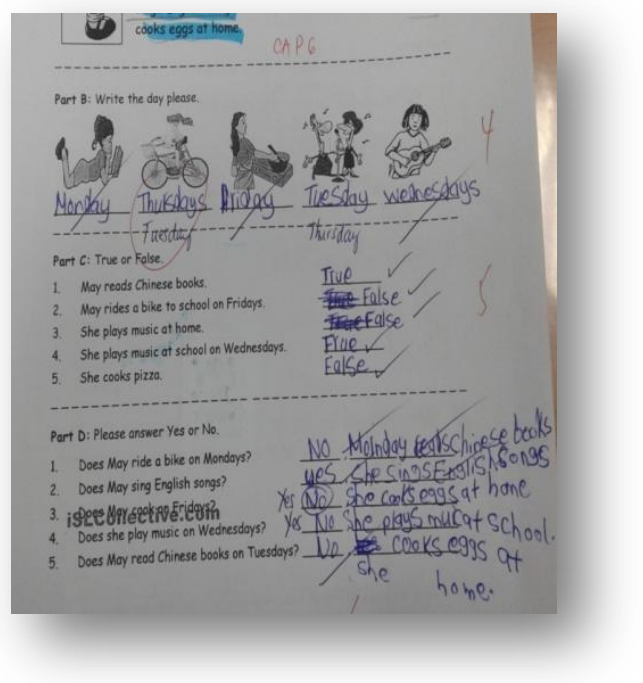

In this sample, CAP 4 matched correctly items A with B. However, erasures suggest hisconfusion.

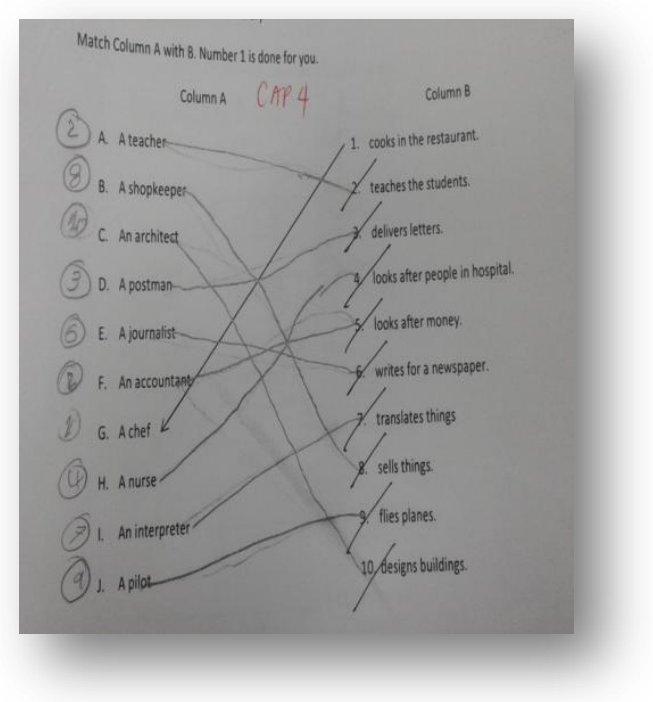

Other students were able to answer short responses; however, answers were incorrect.

In this sample, CAP 3 had 3 mistakes. Comparatively, other participants had similar incorrect answers. Confusion may lead to these mistakes. 


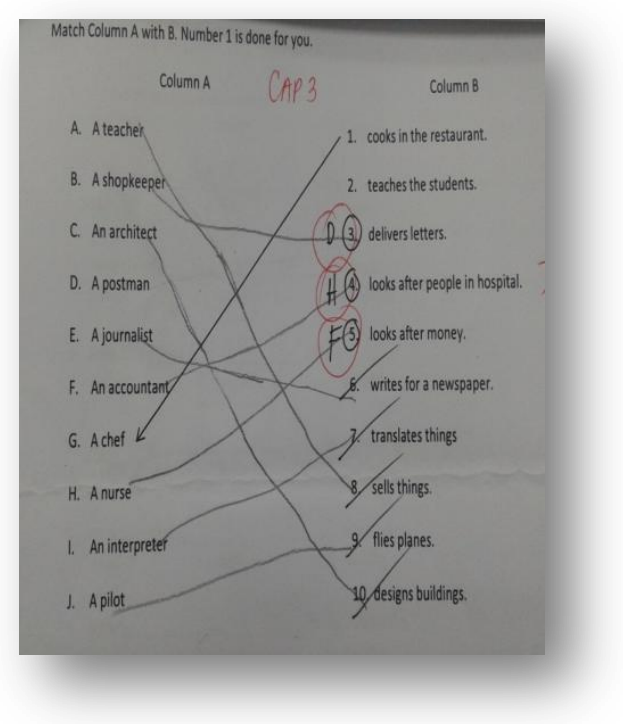

It was noticed in this paper that CAP 7 was able answer the all questions correctly because of the given guide question.

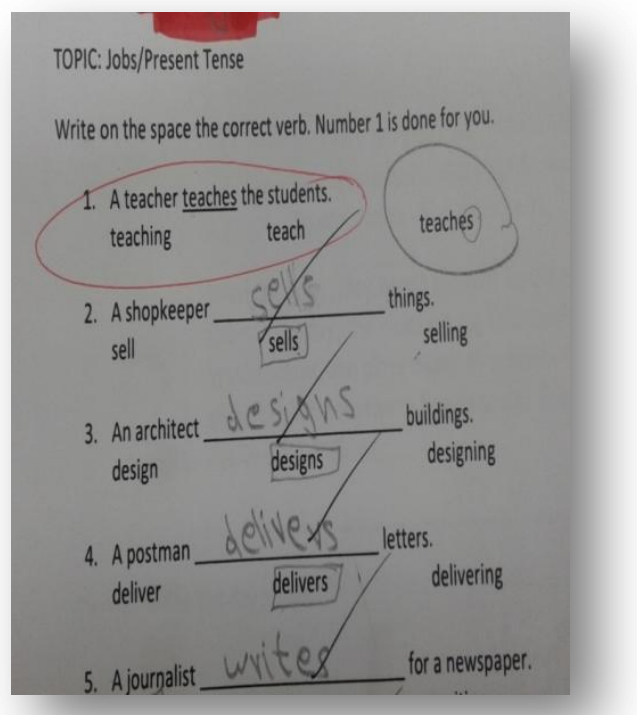

Though learners correctly matched the answers, the erasures on their papers may suggest confusion. On the other hand, learners found no difficulty in literal comprehension with two-option multiple choice. Moreover, giving a model question gave learners advantage in choosing the correct answer.

In this verb be test, CAP 3 together with other participants were able to answer all questions correctly. The examples given steer the participants on how to answer the test. 


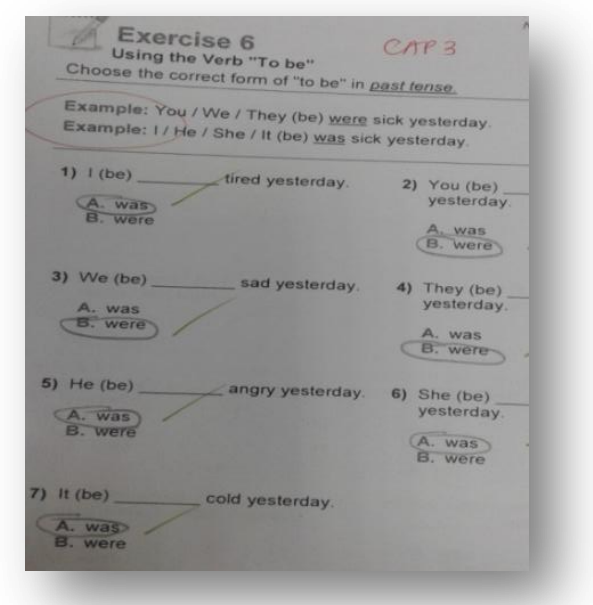

In this short comprehension test, all learners were able to obtain the answers correctly.

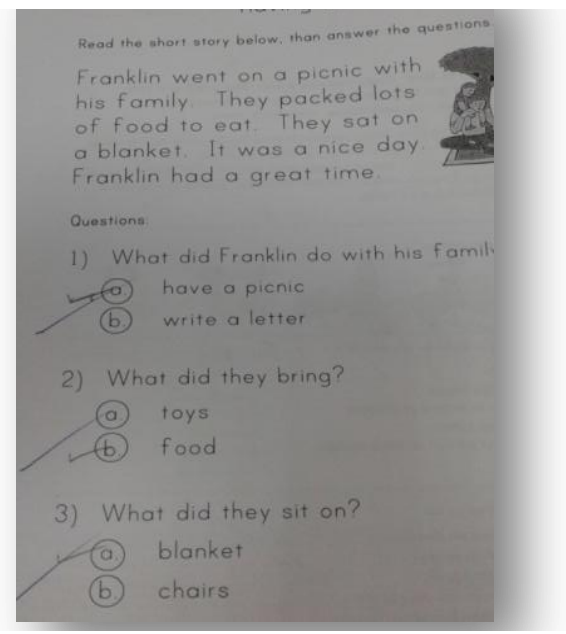

The students could comprehend better with shorter reading materials and two options multiple-choice test.

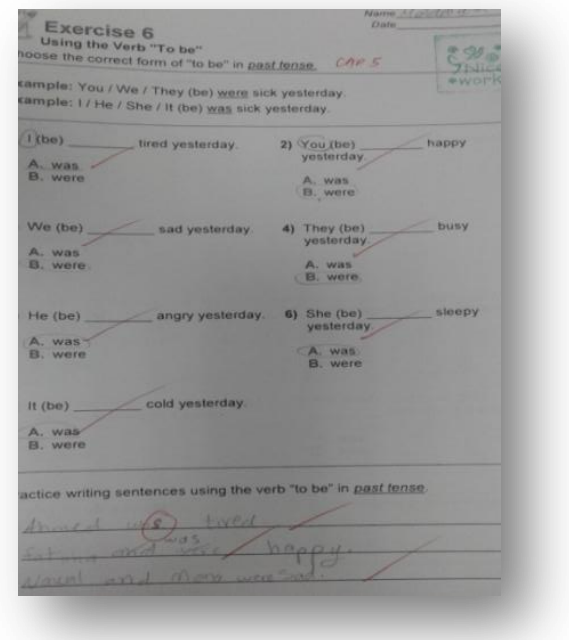

In this sample, CAP6 didn't put punctuation at the end of a sentence. This practice among mute and hard-of-hearing was common. 


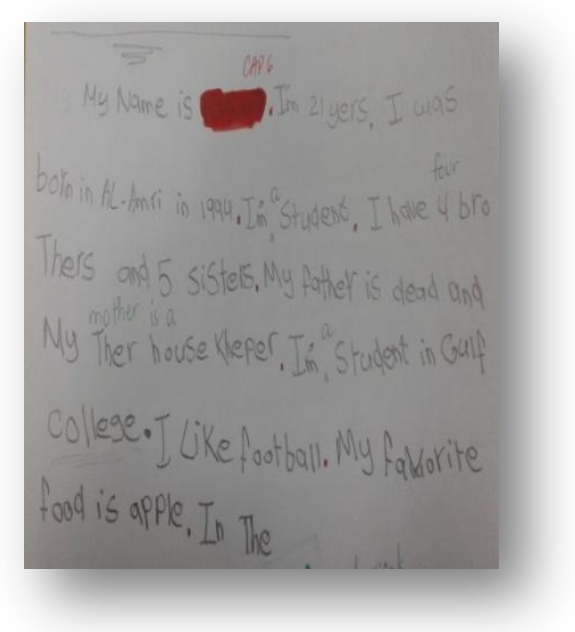

Learners found verb be (present and past) easy.Learners could draw basic or common words. However, learners were unmindful of punctuations like full stop at the end of each sentence.

This sample had similar case with CAP 6. CAP 8 did not punctuate the sentences.

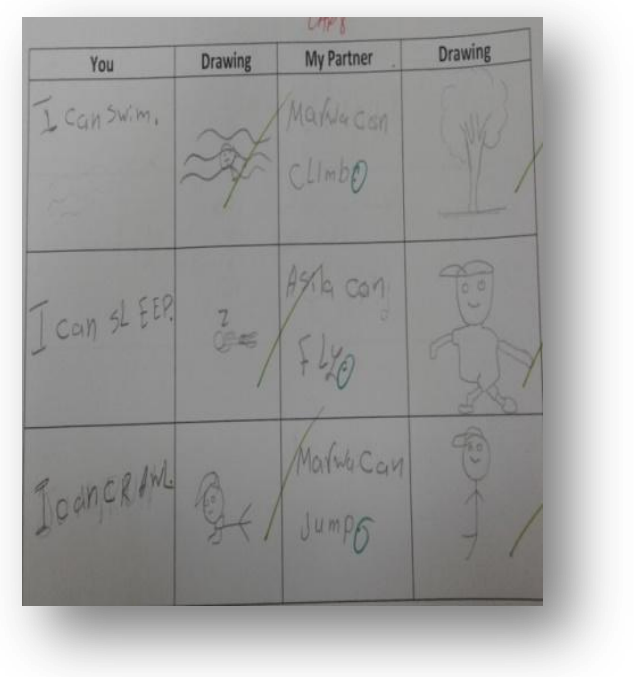

In summary, the results of the short-term classroom assessment showed the cognition and non-cognition of the different aspects of learning. On the positive note mute and hard-of-hearing learners found no or little difficulty in picture name test, yes or no questions, comprehension test with model question, short anecdote reading comprehension, and present and past tenses of (be) verbs. On the other hand, they struggle in answering shortresponses and confused with matching type test. Further, it was observed that students developed techniques in identifying the object. They crossed-out, ticked or numbered the name-word of the object to guide them. Also, they can draw common words which they knew but they were not conscious of the punctuations.

\section{Common Mistakes in Writing:-}

Upon thorough evaluation of the re-written model essays given to the mute and hard-of-hearing learners the following errors in their writings were observed.

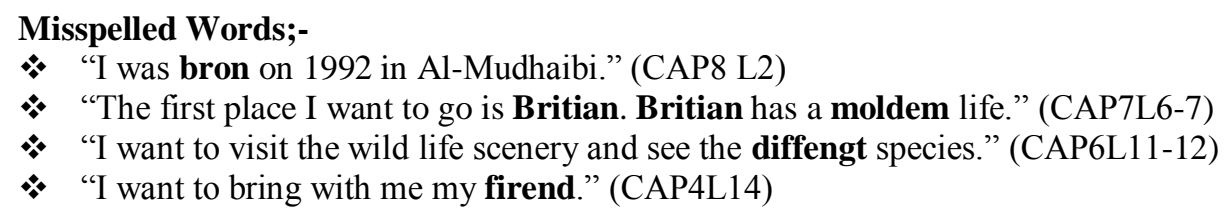


* "I want my childern to study infiet school so that they learn good alues." (CAP3,L15-17)

\section{Omissions:-}

1. "I am Muscat and I am single." (CAP8,L2-3)

2. "My drem gives good visit would be Slalah." (CAP6,13-4)

3. "I want to eat in the restaurants to their delicious food. I want also to a museum and enjoy discovering its history." (CAP5L10-11)

4. "I am livig in Samayhi. I am studying at Golf eg." (CAP4,2-3)

5. "I bought one and try and try and found it vey wonderful. Aftat that time, pizza became my favorite food." CAP2,L1-17)

\section{Addition:-}

1. "I am 22 yeare old." (CAP5L1)"

2. "I want to visit different countries like France, Spani, Brarzil, and Japan." (CAP3,L11-12)"

3. “This food realiyfitts my stomach." (CAP2,L7)

In summary, the deaf and hard-of-hearing learners were comparatively the same with the normal students. They committed misspelled words, omitted some letters of a word or a word itself, and add words in a sentence. The only difference with these learners was, they couldn't entirely decipher the words because of their disability of hearing.

Suggestions for Enhancement:-

\section{Emerging findings out of the content analysis, suggested the following arguments:}

1. Use teaching materials which are in context with the learners. This means that lessons and exercises alike should both include situations and things familiar and common to the learners.

2. All writing exercises may include sample (model) as guide for the learners to look into when answering the test.

3. Written exercises including reading comprehension may only include two-options.

4. Deaf and hard-of-hearing students may be given other test-taking techniques.

5. Lessons on English spelling and punctuations may be reinforced.

6. Short response exercises may be given attention.

7. Matching type test may be modified by not using the arrow system but the letter system. Arrow system may lead to confusion on the part of the test takers.

8. Exercises may adopt the image-test method. This is to enhance the imaginative cognition of the deaf and hardof-hearing learners.

In summary, the above mentioned arguments were formulated based on the analysis of the written exercises and compositions of the deaf and hard-of-hearing students and may not be true and applicable to all deaf and hard-ofhearing learners.

\section{Discussion:-}

This section contains the implications of the findings of the study. This includes literatures which may challenge and favor the result of the study.

\section{Cognition on Short Term Classroom Assessment:-}

The deaf and hard-of-hearing students'performances in all given exercises were generally satisfactory despite of the few errors they committed.However, it was noticeable that their performances in the short-responses were low and word-description matching type was fair. In short responses, most of them fail to write or wrongly responded to the question while in the word-description matching, some did not correctly matched the description with the word. This is an indication that deaf and hard-of-hearing learners may have difficulty in doing short-response tests because they need to digest and comprehend first the questions and provide the answers. This result supports Erting's (1994) finding that mute and hard-of-hearing individuals may 'not comprehend things in depth'. This implies that mute and hard-of-hearing learners cannot fully grasp the idea in the text. Traxler (2000) on the other hand found that deaf individuals cannot acquire understanding of the content of the text because their reading comprehension abilities are below their supposed levels. This is supported by Marschark, Convertino, and LaRock (2006) who observe that deaf individuals have less connective inferencing abilities while reading and solving problems. 
On the other hand, the deaf and hard-of-hearing learners fairly perform in the word description matching because they may not able to recognize some basic words. Domínguez, Carrillo, González, and Alegria (2016) point out that hard-of-hearing learner with or without cochlear implants (CIS) can recognize words and can read sentences using the key word strategy (KWS) which consists of frequently used content words. Content words as defined by Teach in English (2008) are nouns, action verbs, and descriptive words. Thus, the average result of the test may be attributed to unfamiliarity of few learners to the strategy.

With regards to other test results, most learners obtain good marks in picture-identifications, comprehension test in be-verb, true or false, yes or no. According to Marschark (2006) with the onset of sign languages and cognitive inquiry among deaf and hard-of-hearing individuals the idea that these people were less intelligent changed. Deaf and hard-of-hearing individuals are now observed to have good visuo-spatial ability in natural language compare to people with normal people.

It was earlier discussed that mute and hard-of-hearing learners have low comprehension as a result they cannot correctly supply the short response task. However, on the on the context of multiple choice questions where the learners were offered options to choose from, they were able to correctly answer the questions. Thus, it may imply that mute and hard-of-hearing may find difficulty in a reading comprehension but it does not follow in the multiple choice - one statement comprehension. These learners perform better in short comprehension questions rather than in a long story comprehension. Moreover, in the two option tests, mute and hard-of-hearing learners perform very well. This may indicate that teachers of mute and hard-of-hearing learners may consider giving in their assessment test to provide only two choices.

On the other hand, it is noticed that some mute and hard-of-hearing learners have develop a test taking techniques. As observed, learners translate English words into Arabic, numbering the words, and marking the words. By these techniques, learners are able to identify the correct answers. This is a manifestation that these learners either develop these practices or learned from their previous schools. Canadian Hearing Society (2016) pointed out that teach test-taking strategies and techniques are essential for those deaf or hard-of-hearing to make them better prepare.

On the other hand, providing model-sample before the actual test leads the learners to obtain higher scores. The model-sample item becomes the guide of the mute and hard-of-hearing learners to answer the tests. Tim (2008) explained that giving model-sample item's purpose is to prepare and acquaint test-takers to the actual format of the test items.

It isalso observed in the test papers of the mute and hard-of-hearing learners that they can draw common words like nouns. As pointed out by Domínguez, Carrillo, González, and Alegria (2016) that hard-of-hearing learner possessing cochlear implants or not can recognize and read words using the key word strategy (KWS) which consists of frequently used content words. As observe by Mottron, Limoges and Jelenic (2003) deaf and hard-of-hearing individuals display graphic development abilities. This implies that upon learning the words, the mute and hard-ofhearing learners are able to translate the word into its visual representation.

Comparatively with the normal Arabic students, mute and hard-of-hearing learners were not keen on the use of punctuations especially the period or full-stop. According to Aziza (2010) punctuation marks in Arabic language are not always used correctly and Arabic punctuation marks are not similar with the English counterparts. This may be the reason why even the normal students are not used to indicate punctuations in their sentences.

Understanding the language abilities of the mute and hard-of-hearing learners may somehow improve their cognition. Won (1997) suggested that considering and understanding cognition process of mute and hard-of-hearing individuals can lead to their abilities.

\section{Common Mistakes in Writing:-}

The findings of the study showed that misspelled words, omissions and additions were the most common mistakes committed by the mute and hard-of-hearing students. However, literatures found did not specifically showed the factors which contribute to these phenomena in mute and deaf-of-hearing learners. 


\section{Misspelled Words, Omissions, Additions:-}

Fabbretti, Volterra, and Pontecorvo (1998) found that the rate of language development of deaf children was lower compared to children with normal hearing. This result was confirmed by Marschark (2006) who argued that history, psychology and education found hard-of-hearing individuals to be less cognitively flexible compared to hearing individuals. On the other hand, Pardo (1968) said that mute students had slow language comprehension, lack abstraction and formation of concepts, and difficulty in adapting new situations. Kolvin and Fundulis (1981) discovered that mute individuals had evidence of immaturity particularly in speech and excess of speech abnormalities. These literatures summed upthose mute and hard-of-reading learnerswere linguistically challenged. Thus, these learners unlike the normal ones struggle with language.

Arfe, Rossi and Sicoli (2015) found that verbal working memory skills played important role to deaf children's oral and written production. They considered memory skills as determinantsto deaf children's ability to organize oral and written abilities. This was confirmed in the previous study (San Jose, 2016) that mutes and hard-of-hearing learners had weak memory; thus, they easily forget information they obtained from the previous interaction. This implies that the misspelling of words, omissions, and additions were the results of the short and limited memory skills the learners.

In another previous study of Arfe and Perondi (2008) they observed that deaf learners used the same variety of referential devices which were more nominal and less anaphoric. They concluded that writers to have comparable writing abilities with those hearing novice writers. Pie (2011) mentioned that beginning writers often loss their grip of the 'basic writing skills' - can't spell the words correctly, forgot to punctuate and produce incorrect syntax. In other aspect, the common mistake of the learners may be a result of an association on the part of the learners of the English words into their mother tongue, Arabic. Miller (2007) argued that mute and hard-of-hearing learners decoded written words into a code reflecting their native language experience. This implies that because of the variation in languages, phonetics, morphology and syntax may be affected. This result confirmed the previous experience of one of the researchers in this study in Indonesia. Indonesian learners mistakenly write 'apple' into 'apel', 'cable' into 'cabel' and 'grammar' into 'grammer'. This similar observation was found to be consistent with Fabbretti, Volterra and Pontecorvo (1998) who found that deaf learners showed a pattern of selective difficulty with grammar, morphology, particularly with free-standing function words. Lederberg and Spencer (2009) averred that deaf and hard-of-hearing's word-learning abilities were strongly correlated with lexicon size. It showed that acquisition of word-learning skills is based on linguistic mechanisms that are available to children in a wide range of linguistic environments.

\section{Implication for Practice:-}

Teaching the special needs especially the mute and hard-of-hearing learners has notmuch different compared to the normal learners. However, challenges are great and expectations are low. Now, we understand that mute and hardof-hearing's cognition of language may be affected by their exposure to the written and spoken words and their performance is dependent on their memory skills. Thus, as teachers of special needs, our aim is to expose these learners into a classroom environment where they could practice and do activities which could enhance their memory skills. The recommendations mentioned above may be adapted to improve and enhance their language cognition. We understand that the result of this study may not be enough to fathom the comprehension of the mute and hard-of-hearing learners; however, this research may contribute to the understanding of these learners. Thus, more research needs to be conducted to these learners.

\section{References:-}

1. Adams, J., Khan, H. T., \&Raeside, R. (2014). Research methods for business and social science students.SAGE Publications India.

2. Arfé, B., \&Perondi, I. (2008). Deaf and hearing students' referential strategies in writing: What referential cohesion tells us about deaf students' literacy development. First Language, 28(4), 355-374.

3. Arfé, B., Rossi, C., \&Sicoli, S. (2015). The contribution of verbal working memory to deaf children's oral and written production . Journal of deaf studies and deaf education, 20(3), 203-214.

4. Aziza (2010). Punctuation in arabic. Retrieved [Online] http://blogs.transparent.com/arabic/punctuation-inarabic/ on August 23, 2016.

5. Boals, T. (2008).Access for ELLs listening, reading, writing, and speaking.https://www.wida.us/assessment/access/access_sample_items.pdf 
6. Body language (2016).Businessballs.Retrieved http://www.businessballs.com/body-language.htm on August 24, 2016.

7. Brown

K. (2014).

The

limping

chicken. Retrieved

[Online]http://limpingchicken.com/2014/07/10/communication-tips/ August 9, 2016.

8. Canadian Hearing society (2016).Testing accommodation for youth who are deaf or hard of hearing in higher education or workplace.Retrieved https://www.chs.ca/testing-accommodation-youth-who-are-deaf-or-hardhearing-higher-education-or-workplace on August 23, 2016.

9. Domínguez, A. B., Carrillo, M. S., González, V., \&Alegria, J. (2016). How Do Deaf Children With and Without Cochlear Implants Manage to Read Sentences: The Key Word Strategy. Journal of deaf studies and deaf education, enw026.

10. Downe-Wamboldt, B. (1992). Content analysis: method, applications, and issues. Health care for women international, 13(3), 313-321.

11. Duncan, D. F. (1989). Content analysis in health education research: An introduction to purposes and methods. Health Education, 20(7), 27-31.

12. Erting, C. J. (1994). Deafness, communication, and social identity: Ethnography in a preschool for deaf children. Linstok Press.

13. Fabbretti, D., Volterra, V., \&Pontecorvo, C. (1998).Written language abilities in deaf Italians.Journal of Deaf Studies and Deaf Education, 3(3), 231-244.

14. Goldin-Meadow, S. (2005). Hearing gesture: How our hands help us think. Harvard University Press.

15. Hernani, M. E. V. \& Ortega, C. R. (N.D.) Researches of nurses.

16. Humphries, T., Kushalnagar, P., Mathur, G., Napoli, D. J., Padden, C., Rathmann, C., \& Smith, S. R. (2012). Language acquisition for deaf children: Reducing the harms of zero tolerance to the use of alternative approaches.Harm Reduction Journal, 9(1), 1.

17. Kolvin, I., \&Fundudis, T. (1981). Elective mute children: Psychological development and background factors. Journal of Child Psychology and Psychiatry, 22(3), 219-232.

18. Lederberg, A. R., \& Spencer, P. E. (2009). Word-learning abilities in deaf and hard-of-hearing preschoolers: Effect of lexicon size and language modality. Journal of Deaf Studies and Deaf Education, 14(1), 44-62.

19. Marschark, M., Convertino, C., \&LaRock, D. (2006).Optimizing academic performance of deaf students: Access, opportunities, and outcomes. In D. F. Moores\& D. S. Martin (Eds.), Deaf learners: New developments in curriculum and instruction (pp. 179-200). Washington, DC: Gallaudet University Press.

20. Marschark, M. (2006). Intellectual functioning of deaf adults and children: Answers and questions. European Journal of Cognitive Psychology, 18 (1), 70-89.

21. Mathews, E. S. (2011). 'No sign language if you want to get him talking': power, transgression/resistance, and discourses of d/Deafness in the Republic of Ireland. Population, Space and Place, 17(4), 361-376.

22. Miller, P. (2007). The role of spoken and sign languages in the retention of written words by prelingually deafened native signers. Journal of Deaf Studies and Deaf Education, 12(2), 184-208.

23. Mottron, L., LimogeJeles, E., \&Jelenic, P. (2003). Can a cognitive deficit elicit an exceptional ability? A case of savant syndrome in drawing abilities: Nadia. Classic cases in neuropsychology, 2, 323.

24. Pardo, F. M. (1968). Exploration of the intelligence of deaf mute children: Relationship between intelligence and language development. Revista de Psicología General y Aplicada.

25. Pei, L. (2011).On the way to writing.Retrieved [online] https://lpei4.wordpress.com/materials-forteachers/characteristics-of-novice-writers/ on October 1, 2016.

26. San Jose, A. E. (2016). Teaching in a silent classroom: A case study. IOSR Journal Of Humanities And Social Science (IOSR-JHSS) Volume 21, Issue8, Ver. 7 (Aug. 2016) PP 89-96 e-ISSN: 2279-0837, p-ISSN: 22790845. www.iosrjournals.org

27. San Jose, A.E. (2014). Maintenance, improvement, and supervision of parks and playgrounds in Davao City: An evaluative study.International Journal of Development and Sustainability, Vol. 3 No. 1, pp. 221-230.

28. Svensson, L. (1984). Three Approaches to Descriptive Research.

29. Teach in English (2008). Content words. Retrieved from https://www.teachingenglish.org.uk/article/contentwords on August 22, 2016

30. Traxler, C. B. (2000). Measuring up to performance standards in reading and mathematics: Achievement of selected deaf and hard-of-hearing students in the national norming of the 9th Edition Stanford Achievement Test. Journal of Deaf Studies and Deaf Education, 5, 337- 348.

31. Won, D. (1997). The analysis and interference research on psychological crisis of the deaf students in schools for the deaf and mute (j). Chinese Journal of Special Education, 4, 008. 